\section{Wissenschaft macht Spaß}

_ Eine unserer zentralen Rubriken ist der Wissenschaft gewidmet. Und diese haben wir nun für Sie erneuert. Fundierte Erkenntnisse zum Leseverhalten aus der Leserforschung sowie Ihr Feedback zur ergopraxis waren unsere Quellen, mit denen wir bei der Neukonzeption ganz wissenschaftlich vorgehen konnten.

_ Künftig stellen wir Ihnen Studienergebnisse, Forscher, wissenschaftliches Arbeiten und spannendes Detailwissen aus der internationalen Forschung noch griffiger vor. Auf den Punkt gebrachte Informationen erleichtern Ihnen das Lesen. Bilder fördern Assoziationen und damit das Behalten von Inhalten. Diese Erkenntnisse setzen wir beherzt um. Denn wir sind fest davon überzeugt, dass Wissenschaft Spaß machen kann. Glauben Sie nicht? Dann würden wir Sie ab Seite 12 gerne vom Gegenteil überzeugen.

_ Und wissen Sie, was das Beste ist? Diese „Renovierung“ hat uns richtig viel Spaß gemacht. Wir redeten uns in der Redaktion die Köpfe heiß, diskutierten und lachten über kuriose neue Varianten, die wir dann wieder verwarfen. Und waren am Ende stolz, als wir das Ergebnis in den Händen hielten.

Wir sind gespannt, wie Ihnen das neue Konzept gefällt. Sagen Sie es uns.

Sonnige Grüße

Ihre

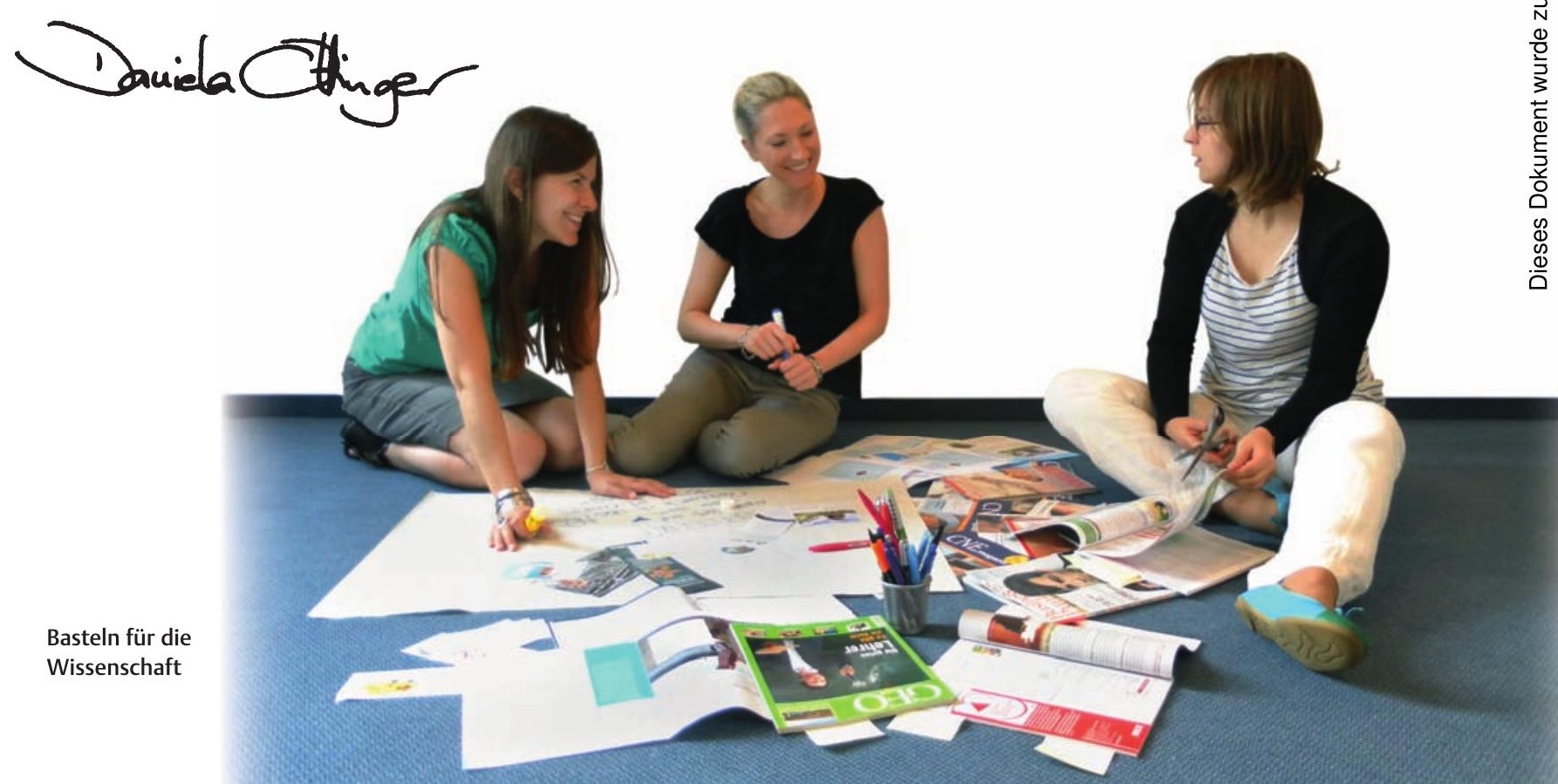

